\title{
Cellulosic Graphene Biocomposites for Versatile High- Performance Flexible Electronic Applications
}

\author{
Pietro Cataldi, Francesco Bonaccorso, Antonio Esau del Rio Castillo, Vittorio Pellegrini, \\ Zhenguo Jiang, Lei Liu, Nicolò Boccardo, Michele Canepa, Roberto Cingolani, \\ Athanassia Athanassiou, and Ilker S. Bayer**
}

Bio-based foldable electrical conductors thanks to their biocompatibility, tunable biodegradation rate, and lightweight are emerging as new-generation components in surgery ${ }^{[1,2]}$ and food packaging. ${ }^{[3]}$ Moreover, they can considerably reduce nondegradable and potentially toxic electronic material waste mainly caused by the whirling race of continuous upgrades in portable electronic devices. ${ }^{[4,5]}$ Among biodegradable and biocompatible polymers, cellulose is the most abundant. ${ }^{[6-8]}$ Aside from its popular and wide use in paper-based printable electronics, ${ }^{[9-12]}$ cellulose is emerging as a key material for new potential applications such as functional flexible and foldable electronics, ${ }^{[13]}$ not only as a substrate. ${ }^{[14]}$ Although cellulose fibers and nano-whiskers have been successfully used as reinforcement for various synthetic ${ }^{[15]}$ and bio-based ${ }^{[7]}$ polymers, to date only a few studies focused on the development of functional composites combining continuous cellulose fiber networks with cellulosic thermoplastic polymers. ${ }^{[16]}$ Despite the fact that cellulose and thermoplastic cellulose derivatives are intrinsically brittle materials, ${ }^{[17-21]}$ when they are in the form of nonwoven microfibers or electrospun nanofibers they show flexibility and foldability similar to cotton fibers. ${ }^{[22,23]}$

Cellulose acetate (CA) is a strong thermoplastic cellulose derivative with a Young's Modulus of about 2 GPa. ${ }^{[24,25]}$ However, pure CA suffers several structural limitations such as brittleness, fracture, and crack propagation under stress. ${ }^{[20,21,26-28]}$ In view of its large-scale use as film or as bulk material for

P. Cataldi, Prof. R. Cingolani, Dr. A. Athanassiou, Dr. I. S. Bayer

Smart Materials

Istituto Italiano di Tecnologia

Via Morego 30, 16163 Genova, Italy

E-mail: ilker.bayer@iit.it

Dr. F. Bonaccorso, Dr. A. Esau del Rio Castillo,

Prof. V. Pellegrini, R. Cingolani

Graphene Labs

Istituto Italiano di Tecnologia

Via Morego 30, 16163 Genova, Italy

Z. Jiang, Prof. L. Liu

Department of Electrical Engineering

University of Notre Dame

Notre Dame, IN 46556, USA

N. Boccardo, M. Canepa, Prof. R. Cingolani

Rehab Laboratories

Istituto Italiano di Tecnologia

Via Morego 30, 16163 Genova, Italy

DOI: 10.1002/aelm.201600245 extrusion, addition of significant amounts of plasticizers is required (up to $30 \mathrm{wt} \%$ ). ${ }^{[29,30]}$ Hence, practically CA is not the most suitable material for the development of flexible and foldable bio-based electronic materials both for its intrinsic rigidity and for several issues linked with plasticizer loss by migration or evaporation over time. ${ }^{[31,32]}$ Nevertheless, CA currently remains to be the most used bio-based polymer for biomedical applications due to its low cost and compatibility with other biomaterials, such as aliphatic-aromatic biodegradable copolymers, ${ }^{[33]}$ chitosan, ${ }^{[34]}$ essential oils, ${ }^{[35]}$ and vitamins ${ }^{[36]}$ just to cite a few. Raw paper, i.e., before the "sizing" process, is however a mere nonwoven cellulose fiber network, which is highly flexible, porous, mechanically robust and chemically resistant. $[8,37,38]$ Thus, the "sizing" process with a bio-based conducting material can result in a foldable biocomposite, showing true isotropic electrical conductivity.

To this end, we demonstrate that cellulose fiber networks can be sized or compounded with CA-graphene based composites, avoiding the use of any plasticizers, resulting in foldable, flexible, and wear abrasion resistant biocomposite electrical conductors. The use of graphene nano-platelet (GnPs) as the filler results in robust, highly conducting, biocompatible, and flexible nanocomposites, behaving like a thin metal foils with excellent mechanical properties and bulk-like electric conductivity. In order to demonstrate their versatility, two applications were chosen both requiring isotropic electrical conduction, namely,

(i) noninvasive electrodes for measuring small stochastic electrical signals generated by muscles (surface electromyography), and

(ii) terahertz (THz) electromagnetic interference (EMI) shields for high speed electronics,

Electromyography $(\mathrm{EMG})^{[39,40]}$ is based on two different approaches to record muscular signals, i.e., by either a needle or a surface electrode. ${ }^{[4-43]}$ These are quite different from the patient's point of view. In fact, the needle electrode method is an invasive and sometimes "unwanted" process, requiring the penetration of the needle itself into the muscle. ${ }^{[41,44,45]}$ On the contrary, the surface electrode method allows for the assessment of the muscle function by recording the muscular activity from the surface skin, ${ }^{[45]}$ thus eliminating the invasive effect of the needle. ${ }^{[4]}$ The current technology is based on the use of metallic plates or buttons attached to the skin by means of an adhesive patch, ${ }^{[47,48]}$ having various limitations in terms of biocompatibility and wearable design. The design of a flexible, thin, disposable, biocompatible and lightweight EMG electrode 
possessing metal-like conductivity can further boost the wide use of such medical devices. For example, flexible and thin EMG electrodes can be attached to the skin over the entire body to monitor muscular activity overcoming the impractical use of rigid and thick metal electrodes especially near the joints. ${ }^{[48]}$ Moreover, flexible, metal-free and thin EMG electrodes can be directly used in vivo to control prosthetic devices. ${ }^{[49,50]}$ It is important to mention that due to the aforementioned materials and design requirements, the use of conductive printed electrodes or circuits on paper, ${ }^{[11,12]}$ may not be a viable option for EMG recording due to the sizing of the paper (impregnation with polymers, ${ }^{[51,52]}$ talc, ${ }^{[53]}$ and starch ${ }^{[54]}$ ) which prevents isotropic conduction throughout the bulk. ${ }^{[55]}$ Also, paper exhibits poor structural stability against water compared to thermoplastic cellulose derivatives. ${ }^{[56,57]}$

The second demonstrator is a THz EMI shield in which the isotropic electrical conductivity (volume conductivity) close to that of a metal is vital for very high-speed circuit operations. ${ }^{[58]}$ It is worth to note how lightweight THz EMI shielding is gaining importance due to increasing speed of electronic systems and circuits in diverse fields, from biological sensing ${ }^{[59]}$ and imaging, ${ }^{[60]}$ to space science ${ }^{[61]}$ and security. ${ }^{[62]}$ Therefore, the exploitation of a foldable cellulosic lightweight biocomposite with $\mathrm{THz}$ EMI shielding capability can enable a range of high-speed circuit applications in the biomaterials field.

The exfoliated GnPs used in this work are platelets of functionalized graphene of thickness ranging from $\approx 2$ to $\approx 15 \mathrm{~nm},{ }^{[63,64]}$ produced as described in refs. $[65,66]$ The systematic study of their Raman and morphological characteristics, such as lateral size and thickness, are presented in the Supporting Information (see Figures S1 and S2). The experimental methods for the biocomposite production are also detailed in the Supporting Information. Biocomposites containing different amounts of GnPs where labeled as CA+GnPX/PCN, where $\mathrm{X}$ indicates the weight percent of GnPs with respect to CA polymer (see Figure S3 in the Supporting Information). PCN designates pristine (untreated) cellulose network substrate over which the coatings were made. After the spray coating deposition, the as prepared samples were heated for $1 \mathrm{~min}$ at $220^{\circ} \mathrm{C}$ (near the melting point of $\mathrm{CA} \approx 230^{\circ} \mathrm{C},{ }^{[67]}$ see Figure S4 in the Supporting Information for thermogravimetric analysis) using a heat gun both to remove any traces of residual solvents (ethanol:acetic anhydride, 1:1) and to soften the CA matrix partially. The photograph in Figure 1a shows the PCN substrate (approximately $40 \mu \mathrm{m}$ thick) before and after the spray coating with the polymer-GnPs dispersion. The biocomposite is folded to demonstrate its flexibility.

We characterized the electrical conductivity of the biocomposites with particular attention to the percolation threshold. ${ }^{68]}$ Figure 1b shows the change in electrical conductivity (as well as sheet resistance) as a function of the volume fraction $(\phi)$ of GnPs. ${ }^{[69]}$ The percolation starts approximately at $\phi=0.03$ corresponding to $5 \mathrm{wt} \% \mathrm{GnPs}$ concentration, a value that confirms earlier reports in literature. ${ }^{[55,69]}$ Before the electrical percolation is reached $(0 \leq \phi \leq 0.03)$, the sheet resistance value is of the order of $10^{9} \Omega / \square$, whereas at the percolation threshold $(\phi=0.03)$, it decreases by two orders of magnitude to $\approx 10^{7}$ $\Omega / \square$. Sheet resistance values of $\approx 10 \Omega / \square$ were obtained with a GnPs concentration of $\approx 30 \mathrm{wt} \%$. The obtained results are
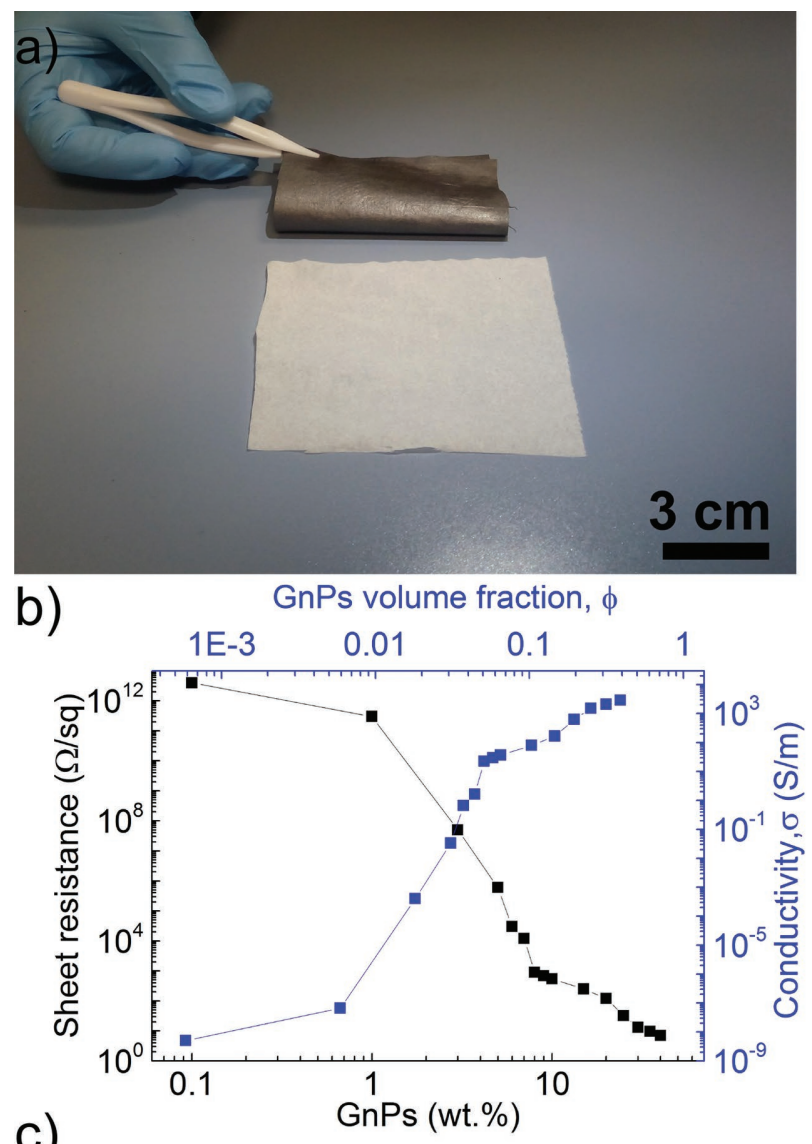

c)

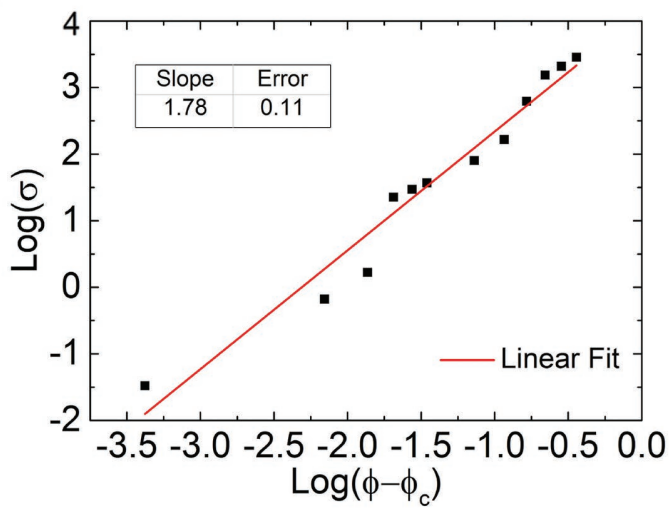

Figure 1. a) Photograph of the nontreated $P C N$ and of the folded $\mathrm{CA}+\mathrm{GnP} 30 / \mathrm{PCN}$ sample. b) Four-probe sheet resistance and electrical conductivity, $\sigma$, measurements as a function of the GnPs wt $\%$ and volume fraction relative to the biopolymer. c) Extraction of electrical transport properties.

in agreement with previous literature reports that compared electrical conductivity $(\sigma)$ of GnP filled composites with other carbon-based fillers such as graphite and carbon black at similar filler concentrations. ${ }^{[55,70]}$ According to the classical percolation theory, ${ }^{[71,72]} \sigma$ is proportional to $\phi$ as follows

$\sigma \propto\left(\phi-\phi_{C}\right)^{\gamma}$

where $\phi_{c}$ is the volume fraction at which the composite starts to conduct electricity, while $\gamma$ represents the universal 
critical exponent, ${ }^{[72,73]}$ which describe the fractal properties of the percolating medium from a macroscopic point of view. Depending on the value assumed by $\gamma$, it is possible to determine the type of percolation: if $\gamma$ has a value of about 1 , the system is considered a $2 \mathrm{D}$ conductor, while if its value is around 2, the system is a 3D conductor, with electrical behavior close to the one of an isotropic conductor. ${ }^{[72,74,75]}$ Literature also reported higher $(>2)$ values of the critical exponent, associated to the presence of defects, ${ }^{[76]}$ charge tunneling, ${ }^{[77]}$ nonhomogeneous inter-particle contact resistances distribution and anisotropy, ${ }^{[78]}$ among other factors. ${ }^{[79,80]}$ Although the application of this theory to conductive composites containing GnPs is only an approximation, it can still be used to estimate the percolation condition at the micro/nano scale. ${ }^{[81,82]}$ As shown in Figure 1c, the estimated value of $\gamma$ correspondent to the slope of $\log (\sigma)$ versus $\log \left(\phi-\phi_{c}\right)$ is close to 2 indicating a 3D percolating system in which the conductive nanomaterials (i.e., GnPs) contact each other throughout the entire polymer matrix. ${ }^{[79,80]}$ This confirms that the biocomposites behave as a bulk conductor, ${ }^{[72]}$ having continuous uninterrupted conductive channels comprising physically connected GnPs within the bulk. ${ }^{[83-85]}$
Biocomposite conductors reported herein display resistance values around $10 \Omega$ (conductivities $>1000 \mathrm{~S} \mathrm{~m}^{-1}$ ) under the optimized polymer-graphene compositions. It is worth noting that various conducting polymers have also been immobilized on cellulose fiber networks or on various paper substrates to achieve flexible cellulose based conductors. A pioneering work by Johnston et al. ${ }^{[86]}$ followed a polymerization approach of conducting monomers/polymers on cellulose fibers. Although they did not report resistance values or mechanical durability of their composites explicitly, they reported conductivity values around $600 \mathrm{~S} \mathrm{~m}^{-1}$. Similarly, Mattoso et al. polymerized aniline monomer on cellulose nanofiber mats and obtained conductors having $1 \mathrm{~S} \mathrm{~m}^{-1}$ conductivity. ${ }^{[87]}$ In one of our previous works, ${ }^{[88]}$ we demonstrated fabrication of highly conductive flexible $\mathrm{SiC}$ paper conductors by tribo-charging and acid doping of polyaniline particles into the texture of the rough paper. Conductivities between 700 and $1000 \mathrm{~S} \mathrm{~m}^{-1}$ were obtained.

The morphological features of the biocomposite and its constituent materials are presented in Figure 2a-c. A dense but porous network of microfibers $(10-40 \mu \mathrm{m})$ constitutes the microstructure of the bare PCN substrate as seen in Figure 2a. Upon spray coating the substrate with cellulose acetate
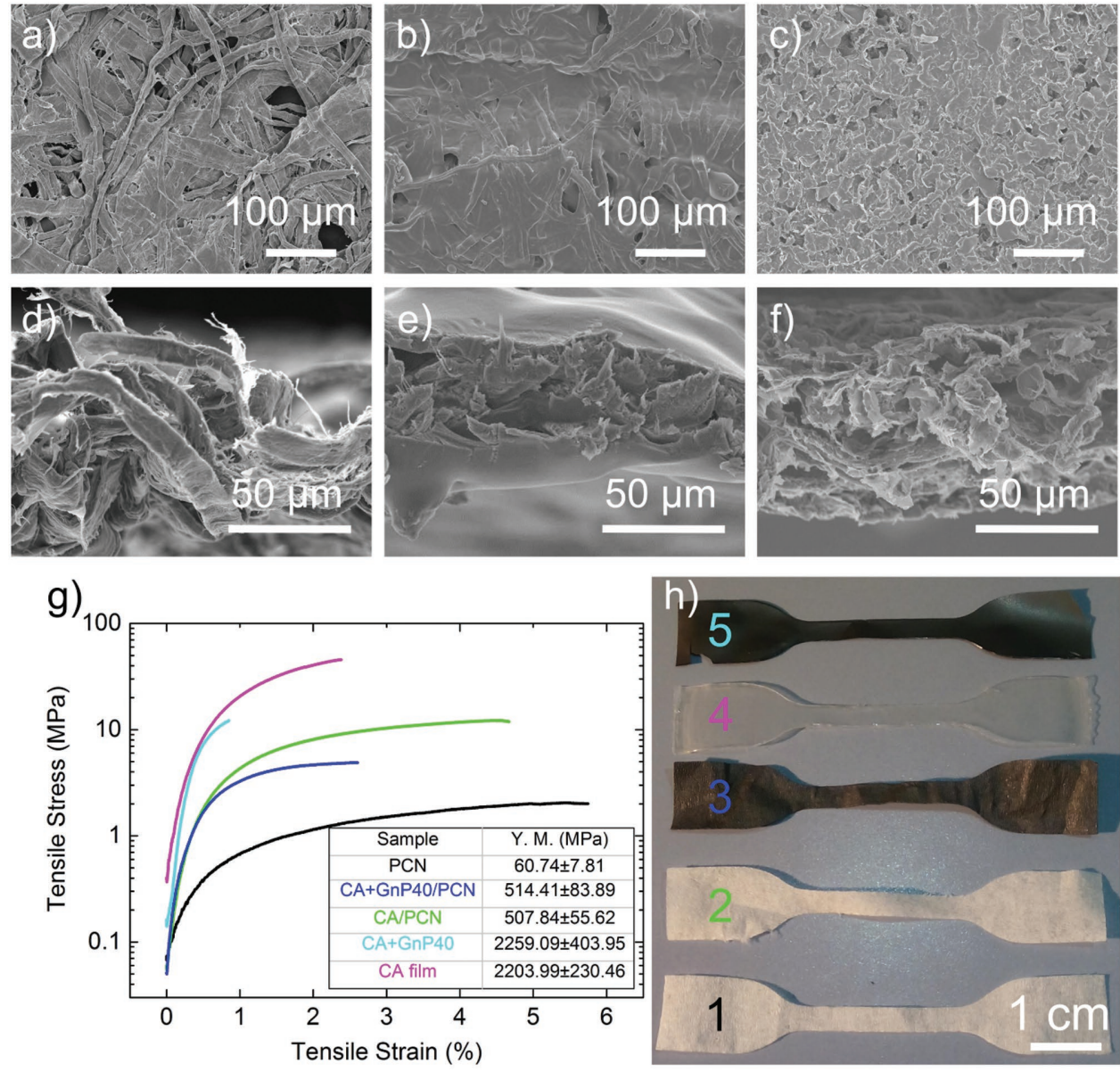

Figure 2. SEM images of the morphology and cross section of biocomposites and their mechanical properties. Images a-c) show the surface morphology of the PCN, CA-sprayed PCN, and CA+GnP40/PCN sample, respectively. Images $\mathrm{d}-\mathrm{f}$ ) are the corresponding cross sections. g) The graph shows tensile strain versus tensile stress measurements. The inset shows the elastic modulus of the samples tested. $h$ ) Photograph of dumbbell-shaped samples: 1. PCN, 2. CA-coated PCN, 3. CA+GnP40/PCN, 4. pure solvent cast CA film, and 5. free standing solvent cast CA+GnP40 film. 
dispersion, the pores are closed and the fibers are encapsulated with the polymer as seen in Figure $2 \mathrm{~b}$. The fibers are no longer visible when PCN is spray coated with the polymer-GnP solution (CA+GnP40/PCN) as seen in the surface scanning electron microscopy (SEM) image in Figure 2c. The cross sections of the aforementioned surfaces are shown in Figure $2 \mathrm{~d}-\mathrm{f}$ in the same order. Pure cellulose substrate, when cut, tends to flake off, forming a disordered fiber network (Figure 2d). On the other hand, as seen in Figure 2e,f, the fiber network is well encapsulated with cellulose acetate polymer or with the CA+GnP40/PCN composite from both sides due to spray coating. Note that, in Figure 2f, CA+GnP40/PCN composite is completely impregnated through the PCN, thus rendering it a truly uniform composite material. Figures S5 and S6 in the Supporting Information display higher magnification SEM images of the biocomposites.

The characterization of the mechanical properties of the conducting foldable biocomposites is important for practical applications. Figure $2 \mathrm{~g}$ reports stress-strain curves of the bare PCN, the free-standing cellulose acetate film, the free standing film of CA with GnPs (CA+GnP40), as well as the CA+GnP40/PCN composite (Table S2 in the Supporting Information lists the thickness information). The Young's modulus of bare PCN was found to be $\approx 61 \mathrm{MPa}$ and it could sustain a maximum stress of $\approx 2 \mathrm{MPa}$ before breaking, whereas when impregnated with the CA polymer its Young's modulus significantly increases reaching $508 \mathrm{MPa}$. The CA+GnP40/PCN biocomposite exhibits similar elastic modulus of $514 \mathrm{MPa}$. The maximum stress before break for the CA/PCN biocomposite increased to $15 \mathrm{MPa}$ and the maximum stress of the $\mathrm{CA}+\mathrm{GnP} 40 / \mathrm{PCN}$ biocomposite was measured to be $5 \mathrm{MPa}$. The bare $\mathrm{PCN}$ elongates $\approx 6 \%$ before rupture; when impregnated with CA, the elongation is reduced to about $4.5 \%$ and with $\mathrm{CA}+\mathrm{GnP} 40$ it further reduces to $2.5 \%$. The reduction in elongation compared to the fiber support is consistent with previous observations $^{[58,89,90]}$ and it is tied to encapsulation of the fibers with CA, which reduces the ability of the nonwoven fibers to transfer stresses. ${ }^{[1,92]}$ Furthermore, the CA+GnP40/PCN and CA/PCN biocomposites have similar elastic moduli, indicating that the presence of GnPs does not change the hardness of the biocomposite. We note that further hardening would have detrimental effects on the biocomposite electrical conductivity, following possible failure during folding-unfolding events. On one hand, the impregnation of the PCN with GnPs induces isotropic electrical conductivity of the composite material, and on the other it still maintains the elastic moduli of GnPs free CA/ PCN biocomposite. Note that pure and free-standing CA and $\mathrm{CA}+\mathrm{GnP} 40$ composite films have Young's moduli of 2.2 and
2.3 GPa, respectively, the latter being the most brittle, showing an elongation less than $1 \%$. Photographs of the tested dumbbell samples are shown in Figure $2 \mathrm{~h}$.

The folding stability and the resistance to wear abrasion of the biocomposites are reported in Figure 3. Measurements were repeated in at least five samples. The electrical resistance of the biocomposites increases under continuous foldingunfolding or abrasion under $20 \mathrm{kPa}$. Folding-unfolding events, for a total of 40 cycles, were carried out following two procedures, as seen in Figure 3a. During the first 20 cycles, a weight of $5 \mathrm{~kg}$ was applied and run alongside the fold mark and upon unfolding the electrical resistance was measured across the folded region. After the 10th folding event, the sheet resistance was stable, reaching a plateau. Therefore, for the last 20 cycles, the samples were merely folded and unfolded without applying an additional force alongside the folded region. The changes in the electrical resistance across the fold mark are plotted as the ratio $\rho=R_{\mathrm{i}} / R_{0}$ for the case of $\mathrm{CA}+\mathrm{GnP} 40 / \mathrm{PCN}$ sample, where 
$R_{\mathrm{i}}$ is the sheet resistance at the $i$ th cycle of folding-unfolding sequence and $R_{0}$ is the initial sheet resistance. During the first 10 cycles, $\rho$ reached to $\approx 1.8$ almost double; however, this increase is not a big loss in conductivity such as an order of magnitude change. To further demonstrate the mechanical robustness of our as-prepared GnPs-based biocomposite, the inset photo in Figure 3a (see Video file V1 in the Supporting Information), shows how the $\mathrm{CA}+\mathrm{GnP} 40 / \mathrm{PCN}$ composite lit up a light-emitting diode (LED) even under a compressed ball-like folded state, showing similar performance as for the unfolded composite. Investigation of the morphological changes across the fold mark was made by SEM as shown in Figure 3b,c. After the 10th fold cycle, it is possible to identify the formation of a crack. However, the crack appears to be only on the surface of the $\mathrm{CA}+\mathrm{GnP} 40 / \mathrm{PCN}$ composite, thus not altering the isotropic electrical conductivity preserving the conductive paths.

Wear abrasion resistance tests results are shown in Figure 3d, in which three different conductive biocomposites were tested, namely $\mathrm{CA}+\mathrm{GnP} 20 / \mathrm{PCN}, \mathrm{CA}+\mathrm{GnP} 30 / \mathrm{PCN}$, and $\mathrm{CA}+\mathrm{GnP} 40 / \mathrm{PCN}$ with decreasing electrical resistance, as shown in Figure 1b. Up to $30 \mathrm{~min}$ of abrasion tests were carried out using a plastic abrasive disk under pressure. The sheet resistance of the samples increases as the abrasion time increases under the given applied pressure $(20 \mathrm{kPa})$. In the case of conducting biocomposites (CA+GnP30/PCN and $\mathrm{CA}+\mathrm{GnP} 40 / \mathrm{PCN}$ ), the sheet resistance roughly doubled its initial value (from 15 to $40 \Omega / \square$ for CA+GnP30/PCN and from 10 to $25 \Omega / \square$ for CA+GnP40/PCN). We note that, the increase in sheet resistance, i.e., from 120 to $135 \Omega / \square$, is less marked for the biocomposite $(\mathrm{CA}+\mathrm{GnP} 20 / \mathrm{PCN})$ having higher sheet resistance. A possible explanation could be given by considering that at high $\mathrm{GnP}$ loadings, many more interfaces form between the binding polymer matrix and the GnPs which can fail by separation and wear under harsh abrasive conditions. Nonetheless, as seen in Figure 2, due to the architecture of the biocomposites such as the good compatibility between two cellulosic materials (cellulose fiber network and cellulose acetate matrix) and high Young's modulus of CA prevent severe conductive failures under the abrasion conditions studied herein. ${ }^{90]}$

Given their robust mechanical resistance and resilience to severe folding conditions, our new biocomposites become appealing candidates for both heavy duty medical and electronic applications. In what follows, we demonstrate two proof of principle devices: (i) biocomposite thin flexible electromyography (EMG) electrodes, and (ii) a biocomposite $\mathrm{THz}$ shield.

Biocomposite Myoelectric Contacts: Thin flexible electromyography electrodes can be obtained by using $\mathrm{CA}+\mathrm{GnP} 40 / \mathrm{PCN}$ sheets in direct contact with the patient skin. We fabricated three flexible electrodes based on the $\mathrm{CA}+\mathrm{GnP} 40 / \mathrm{PCN}$ composite (conductivity $=10^{3} \mathrm{~S} \mathrm{~m}^{-1}$ ), in order to compare the performance with the bulky titanium (Ti) (conductivity $\left.=10^{6} \mathrm{~S} \mathrm{~m}^{-1}\right)^{[93]}$ rigid electrodes, commonly used in EMG (Figure 4a). Note that isotropic (metal-like bulk) conductivity is essential for such an experiment. For the EMG measurements, the GnPs-based biocomposites were directly connected to the amplifier circuit, in a configuration identical to the one used for the standard Ti electrodes. Afterwards, the two electrodes (the standard Ti-based and the GnPs-based biocomposite) were placed over a human forearm
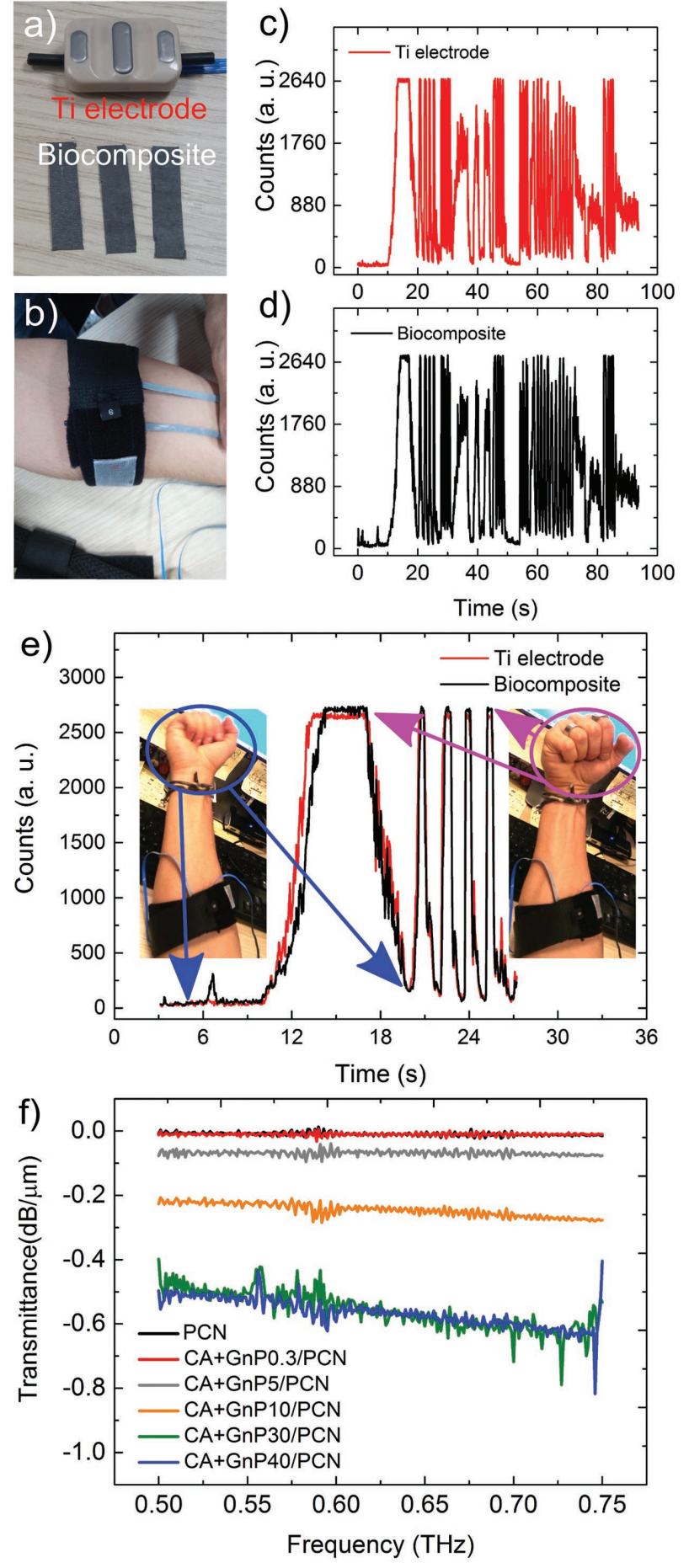

Figure 4. a) Photograph showing a standard electromyography Ti electrode $(\approx 500 \mu \mathrm{m})$ in comparison with the thin $(\approx 70 \mu \mathrm{m}) \mathrm{CA}+\mathrm{GnP} 40 / \mathrm{PCN}$ biocomposite. b) Photograph displaying both electrodes strapped to the arm side by side. c) Signals obtained from the Ti electrode. d) Signals obtained from the biocomposite. e) Superimposed signals from both electrodes corresponding to the first $28 \mathrm{~s}$ portion of the experiment. The signal rests at zero when the wrist is not flexed (see inset on the left). The signal somewhat exceed 2500 counts and the wrist if flexed (inset on the right). The zone between 10-20 s time intervals corresponds to holding the wrist flexed. f) Terahertz EMI shielding characteristics of the biocomposites in terms of frequency-dependent transmittance. 
side by side and fastened with a strip (Figure $4 \mathrm{~b}$ ). As the arm was flexed, the signal was measured simultaneously with both electrodes and then stored for further analysis (see Experimental Section). Figure $4 c, d$ display the signals measured by both electrodes (standard Ti-based: red signal and GnPs-based biocomposite: black signal) as function of time. The shape of the acquired signals is almost identical as well as their relative intensities and the saturation point at 2640 , i.e., the maximum of the scale expressed in arbitrary units. The comparable performances of the two tested electrodes are further confirmed by enlarging and overlapping a part of the recorded traces (see Figure 4e). Herein, the signals from both electrodes in the 3-28 s time interval are superimposed, showing similar profile. The slight difference detected can be attributed to the fact that the electrodes cannot, physically, monitor simultaneously the same spot on the muscle due to their finite size (in the order of tens of millimeters). The inset photographs to Figure $4 \mathrm{e}$ show the location of the signals corresponding to movement of the wrist. Namely, when the wrist is relaxed the signal is almost equal to zero, while when it moves or contracts, the signal is at $\approx 2640$ in both cases. Note also that if the wrist is kept at a flexed position for some time (in this case longer than $6 \mathrm{~s}$ in Figure 4e), the signal does not decay and remains constant, identical to the Ti electrode. Hence, the biocomposite electrodes are as efficient as the thick $(\approx 500 \mu \mathrm{m})$ Ti block electrodes as shown in Figure 4a. This demonstration proves that these flexible biocomposites can be potentially used as wearable conductors for acquiring biomedical signals. As such, a lightweight, isotropic, flexible and potentially wearable conductor can offer many advantages, with respect to the current technology, for electro-diagnostic monitoring. For further details on the behavior of biocomposites with lower GnP concentration Figure S7 in the Supporting Information can be referred.

Biocomposite THz Shields: Successful THz performance of thin and flexible isotropic metal-like conductors is imperative for broadband communications and high-speed electronics in which expensive and corrosion-prone metallic conductors can be replaced with such biocomposites. The EMI shielding measurements were carried out at frequencies exceeding the upper limits of the microwave $\mathrm{W}$ band $(0.5-0.75 \mathrm{THz}$; see Figure $4 \mathrm{f})$, which is an order of magnitude higher than the satellites communication range $(\approx 0.05 \mathrm{THz} ; \mathrm{V}$ band). The reader can refer to Figure S8 in the Supporting Information for further details on the EMI measurements. The EMI shielding effectiveness (SE; i.e., sum of all the losses of the incoming electromagnetic wave due to screening $\left.{ }^{(94)}\right)$ is calculated using $\mathrm{SE}(\mathrm{dB})=-10 \log \left(P_{T} / P_{\mathrm{I}}\right)$, where $P_{\mathrm{T}}$ is the transmitted electromagnetic power and $P_{I}$ is the incident power. ${ }^{[62,95]}$ The ratio $P_{T} / P_{I}$ (also called transmittance T-SE in $\mathrm{dB}$ ) is a function of the frequency of the incident electromagnetic wave. In Figure $4 \mathrm{f}$, we report the EMI SE (i.e., the absolute value of $T$ ) per unit length versus the frequency (from 0.5 to $0.75 \mathrm{THz}$ ) of the incoming electromagnetic waves for the aforementioned samples. The transmittance has a constant value over the investigated frequency range $(0.5-0.75 \mathrm{THz})$ (slightly lower transmittance expected following the well-known Druid model ${ }^{[96]}$ ). The average SE value increased from $0 \mathrm{~dB} \mu \mathrm{m}^{-1}$ for the control PCN sample to $0.6 \mathrm{~dB} \mu \mathrm{m}^{-1}$ for the $\mathrm{CA}+\mathrm{GnP} 30 / \mathrm{PCN}$ and $\mathrm{CA}+\mathrm{GnP} 40 / \mathrm{PCN}$ biocomposites. The obtained results are in line with literature values reported for

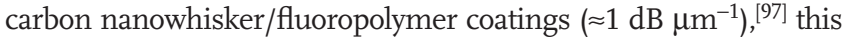
means that in our case, considering for example the thickness of the CA+GnP40/PCN sample $(\approx 70 \mu \mathrm{m}$, see Figure $2 \mathrm{f})$, the $\mathrm{SE}$ assumes a value of $40 \mathrm{~dB}$ significantly exceeding the lowest threshold value of EMI SE (20 dB, $\leq 1 \%$ transmittance of electromagnetic wave) required for commercial applications. ${ }^{[95,98,99]}$ Note that both $\mathrm{CA}+\mathrm{GnP} 30 / \mathrm{PCN}$ and $\mathrm{CA}+\mathrm{GnP} 40 / \mathrm{PCN}$ biocomposites have similar EMI shielding performance. Experiments reported in Figure 1b indicate how the electrical conductivity of the biocomposites does not significantly increase with a GnP concentration exceeding 30\%. EMI shielding measurements at high $\mathrm{GHz}$ frequencies are complex and influenced by noise associated with the measurements themselves as well as variations in sample thickness. However, samples having close electrical conductivity values would produce similar EMI shielding performances ${ }^{[83,84]}$ As reported in Figure $4 \mathrm{f}$, both samples produce satisfactory THz shielding effectiveness. Therefore, the biocomposites display a shielding effectiveness corresponding to $0.5 \mathrm{~dB} \mu \mathrm{m}^{-1}$, which is above the generally accepted threshold transmittance of $0.2 \mathrm{~dB} \mu \mathrm{m}^{-1}$. It is worth to note that the percentage of GnPs reported so far is based on CA polymer weight on dry basis. However, if the weight of the PCN is also taken into account, weight percent of GnP with respect to the total cellulosic compounds in the biocomposite is halved. Generally, for EMI shielding experiments on composites and reported in literature, the weight percent or fraction of the conductive components is reported with respect to the total weight of the composite. ${ }^{[62,95,99,100]}$

In summary, we fabricated lightweight all cellulose based biocomposite conductors with graphene nanoplatelets. Due to their low sheet resistance value, $\approx 10 \Omega / \square$, they performed as efficient as bulky metallic (Ti) electrodes for biomedical signal acquisition. The biocomposites demonstrated remarkable terahertz EMI shielding capabilities. Contrary to conductive Xerox paper, the proposed graphene nanoplatelets-based biocomposites feature isotropic bulk electrical conductivity and better water-proof resistance. Moreover, graphene nanoplatelets-based biocomposites demonstrate remarkable robust mechanical resistance against severe (weight pressed) folding-unfolding cycles as well as wear abrasion under $20 \mathrm{kPa}$ applied pressure. Due to their lightweight, biodegradability, flexibility coupled with mechanical robustness, and quasi-metal electrical conductivity values, these biocomposites can be used in a variety of high-speed applications ranging from wearable electronics, electro-diagnostic medicine, aerospace, and security.

\section{Supporting Information}

Supporting Information is available from the Wiley Online Library or from the author.

\section{Acknowledgements}

The authors acknowledge constant support from Dr. Massimiliano Bianchi and Dr. Laura Rizzi of DIRECTA PLUS S.p.A. and funding from the European Union's Horizon 2020 research and innovation program under grant agreement No 696656-GrapheneCore1.

Received: June 22, 2016 Revised: September 11, 2016 Published online: 
[1] Y. Xiao, S. Zhou, L. Wang, T. Gong, ACS Appl. Mater. Interfaces 2010, 2, 3506.

[2] I. Cucchi, A. Boschi, C. Arosio, F. Bertini, G. Reddi, M. Catellan, Synth. Met. 2009, 159, 246

[3] W. S. Wong, A. Salleo, Flexible Electronics: Materials and Applications, Vol. 11, Springer Science \& Business Media, 2009.

[4] M. Irimia-Vladu, E. D. Gowacki, G. Voss, S. Bauer, N. S. Sariciftci, Mater. Today 2012, 15, 340.

[5] M. Irimia-Vladu, Chem. Soc. Rev. 2014, 43, 588.

[6] R. J. Moon, A. Martini, J. Nairn, J. Simonsen, J. Youngblood, Chem. Soc. Rev. 2011, 40, 3941.

[7] H. A. Khalil, A. Bhat, A. I. Yusra, Carbohydr. Polym. 2012, 87, 963.

[8] T. Huber, J. Müssig, O. Curnow, S. Pang, S. Bickerton, M. P. Staiger, J. Mater. Sci. 2012, 47, 1171.

[9] A. Rida, L. Yang, R. Vyas, M. M. Tentzeris, IEEE Antennas Propag. Mag. 2009, 51, 13.

[10] Z. Weng, Y. Su, D.-W. Wang, F. Li, J. Du, H.-M. Cheng, Adv. Energy Mater. 2011, 1, 917.

[11] R. Martins, I. Ferreira, E. Fortunato, Physica Status Solidi (RRL)Rapid Res. Lett. 2011, 5, 332.

[12] D. Tobjörk, R. Österbacka, Adv. Mater. 2011, 23, 1935.

[13] Z. Fang, H. Zhu, C. Preston, X. Han, Y. Li, S. Lee, X. Chai, G. Chen, L. Hu, J. Mater. Chem. C 2013, 1, 6191.

[14] N. Lin, A. Dufresne, Eur. Polym. J. 2014, 59, 302.

[15] A. Bledzki, J. Gassan, Prog. Polym. Sci. 1999, 24, 221.

[16] K. C. Seavey, I. Ghosh, R. M. Davis, W. G. Glasser, Cellulose 2001, 8, 149.

[17] J. Pang, X. Liu, X. Zhang, Y. Wu, R. Sun, Materials 2013, 6, 1270.

[18] X. Liu, J. Pang, X. Zhang, Y. Wu, R. Sun, Cellulose 2013, 20, 1391.

[19] C. S. Achoundong, N. Bhuwania, S. K. Burgess, O. Karvan, J. R. Johnson, W. J. Koros, Macromolecules 2013, 46, 5584.

[20] S. Hooshmand, Y. Aitomäki, M. Skrifvars, A. P. Mathew, K. Oksman, Cellulose 2014, 21, 2665.

[21] C. Pang, R. A. Shanks, F. Daver, Comp. Part A: Appl. Sci. Manuf. 2015, 70, 52.

[22] T. Christoforou, C. Doumanidis, J. Nanosci. Nanotechnol. 2010, 10, 6226.

[23] A. Baptista, J. Martins, E. Fortunato, R. Martins, J. Borges, I. Ferreira, Biosens. Bioelectron. 2011, 26, 2742.

[24] C. M. Buchanan, R. M. Gardner, R. J. Komarek, J. Appl. Polym. Sci. 1993, 47, 1709.

[25] H. Warth, R. Mälhaupt, J. Schätzle, J. Appl. Polym. Sci. 1997, 64, 231.

[26] A. Mohanty, A. Wibowo, M. Misra, L. Drzal, Polym. Eng. Sci. 2003, 43,1151

[27] P. Jandura, B. Riedl, B. V. Kokta, Polym. Degrad. Stab. 2000, 70, 387.

[28] A. K. Mohanty, M. Misra, G. Hinrichsen, Macromol. Mater. Eng. 2000, 276, 1 .

[29] J.-H. Guo, Drug Dev. Ind. Pharm. 1993, 19, 1541.

[30] P. Rao, P. V. Diwan, Pharm. Acta Helv. 1997, 72, 47.

[31] L. Castle, A. J. Mercer, J. R. Startin, J. Gilbert, Food Addit. Contam. 1988, 5, 9.

[32] E. Richardson, M. T. Giachet, M. Schilling, T. Learner, Polym. Degrad. Stab. 2014, 107, 231.

[33] C.-S. Wu, Carbohydr. Polym. 2012, 87, 1249.

[34] C. Liu, R. Bai, J. Membr. Sci. 2005, 267, 68.

[35] I. L. Liakos, F. D'autilia, A. Garzoni, C. Bonferoni, A. Scarpellini, V. Brunetti, R. Carzino, P. Bianchini, P. P. Pompa, A. Athanassiou, Int. J. Pharm. 2016, 510, 508.

[36] P. Taepaiboon, U. Rungsardthong, P. Supaphol, Eur. J. Pharm. Biopharm. 2007, 67, 387.

[37] G. Helenius, H. Bäckdahl, A. Bodin, U. Nannmark, P. Gatenholm, B. Risberg, J. Biomed. Mater. Res. Part A 2006, 76, 431.
[38] C. Miao, W. Y. Hamad, Cellulose 2013, 20, 2221.

[39] A. Richardson, Rheumatology 1952, 1, 88.

[40] D. Tan, T. S. Saponas, D. Morris, J. Turner, Wearable electromyography-based controllers for human-computer interface, US Patent 8, 170, 656, 2012.

[41] R. H. Chowdhury, M. B. Reaz, M. A. B. M. Ali, A. A. Bakar, K. Chellappan, T. G. Chang, Sensors 2013, 13, 12431.

[42] R. Merletti, A. Holobar, D. Farina, J. Electromyog. Kinesiol. 2008, 18, 879.

[43] G. L. Soderberg, T. M. Cook, Phys. Therapy 1984, 64, 1813.

[44] A. J. Boon, J. T. Gertken, J. C. Watson, R. S. Laughlin, J. A. Strommen, M. L. Mauermann, E. J. Sorenson, Muscle Nerve 2012, 45, 9.

[45] D. Farina, F. Negro, IEEE Rev. Biomed. Eng. 2012, 5, 3.

[46] B. G. Lapatki, R. Oostenveld, J. P. Van Dijk, I. E. Jonas, M. J. Zwarts, D. F. Stegeman, Psychophysiology 2010, 47, 299.

[47] K.-P. Hoffmann, R. Ruff, in Eng. Med. Biol. Soc., 2007 (EMBS 2007). 29th Annual International Conference of the IEEE, IEEE, 2007, pp. 5739-5742.

[48] B. G. Lapatki, J. P. Van Dijk, I. E. Jonas, M. J. Zwarts, D. F. Stegeman, J. Appl. Physiol. 2004, 96, 327.

[49] H.-J. Huppertz, C. Disselhorst-klug, J. Silny, G. Rau, G. Heimann, Muscle Nerve 1997, 20, 1360.

[50] M. Zecca, S. Micera, M. Carrozza, P. Dario, Crit. Rev. Biomed. Eng. 2002, 30, 459.

[51] Y.-h. Guo, J.-j. Guo, S.-c. Li, X. Li, G.-s. Wang, Z. Huang, Colloids. Surf. A: Physicochem. Eng. Aspects 2013, 427, 53.

[52] M. Jonoobi, Y. Aitomäki, A. P. Mathew, K. Oksman, Comp. Part A: Appl. Sci. Manuf. 2014, 58, 30.

[53] M. M. Ibrahim, F. Mobarak, E. I. S. El-Din, A. E-H. E. Ebaid, M. A. Youssef, Carbohyd. Polym. 2009, 75, 130.

[54] H. W. Maurer, R. L. Kearney, Starch-Stärke 1998, 50, 396.

[55] P. Cataldi, I. S. Bayer, F. Bonaccorso, V. Pellegrini, A. Athanassiou, R. Cingolani, Adv. Electron. Mater. 2015, 1, 12.

[56] X. Li, J. Tian, W. Shen, Cellulose 2010, 17, 649.

[57] K. L. Kato, R. E. Cameron, J. Appl. Polym. Sci. 1999, 74, 1465.

[58] P. Saini, V. Choudhary, J. Nanopart. Res. 2013, 15, 1.

[59] E. Brown, E. A. Mendoza, D. Xia, S. Brueck, IEEE Sens. J. 2010, 10, 755.

[60] L. Liu, H. Xu, A. W. Lichtenberger, R. M. Weikle II, IEEE Trans. Microwave Theory Tech. 2010, 58, 1943.

[61] P. H. Siegel, IEEE Trans. Microwave Theory Tech. 2002, 50, 910.

[62] L. Liu, A. Das, C. M. Megaridis, Carbon 2014, 69, 1.

[63] S. Casaluci, M. Gemmi, V. Pellegrini, A. Di Carlo, F. Bonaccorso, Nanoscale 2016, 8, 5368.

[64] S. Mathew, A. Yella, P. Gao, R. Humphry-Baker, B. F. Curchod, N. Ashari-Astani, I. Tavernelli, U. Rothlisberger, M. K. Nazeeruddin, M. Grätzel, Nat. Chem. 2014, 6, 242.

[65] M. Yi, Z. Shen, J. Mater. Chem. A 2015, 3, 11700.

[66] Y. Yao, Z. Lin, Z. Li, X. Song, K.-S. Moon, C.-p. Wong, J. Mater. Chem. 2012, 22, 13494.

[67] H. Liu, Y.-L. Hsieh, J. Polym. Sci. Part B: Polym. Phys. 2002, 40, 2119.

[68] Z.-M. Dang, Y.-H. Zhang, S.-C. Tjong, Synth. Metals 2004, 146, 79.

[69] S. Stankovich, D. A. Dikin, G. H. Dommett, K. M. Kohlhaas, E. J. Zimney, E. A. Stach, R. D. Piner, S. T. Nguyen, R. S. Ruoff, Nature 2006, 442, 282.

[70] M. Blaszkiewicz, D. S. McLachlan, R. E. Newnham, Polym. Eng. Sci. 1992, 32, 421.

[71] J. W. Essam, Rep. Prog. Phys. 1980, 43, 833.

[72] H. Pang, T. Chen, G. Zhang, B. Zeng, Z.-M. Li, Mater. Lett. 2010, 64, 2226.

[73] T. Kuilla, S. Bhadra, D. Yao, N. H. Kim, S. Bose, J. H. Lee, Prog. Polym. Sci. 2010, 35, 1350.

[74] W. Bauhofer, J. Z. Kovacs, Comp. Sci. Technol. 2009, 69, 1486. 
[75] A. Combessis, L. Bayon, L. Flandin, Appl. Phys. Lett. 2013, 102, 011907.

[76] B. Halperin, S. Feng, P. Sen, Phys. Rev. Lett. 1985, 54, 2391.

[77] I. Balberg, Phys. Rev. Lett. 1987, 59, 1305.

[78] P. M. Kogut, J. P. Straley, J. Phys. C: Solid State Phys. 1979, 12, 2151.

[79] A. Celzard, J. Marêché, Phys. A: Stat. Mech. Appl. 2003, 317, 305.

[80] M. B. Heaney, Phys. Rev. B 1995, 52, 12477.

[81] G. Cunningham, M. Lotya, N. McEvoy, G. S. Duesberg, P. van der Schoot, J. N. Coleman, Nanoscale 2012, 4, 6260.

[82] Y. Zhan, M. Lavorgna, G. Buonocore, H. Xia, J. Mater. Chem. 2012 22, 10464.

[83] Z. Chen, C. Xu, C. Ma, W. Ren, H.-M. Cheng, Adv. Mater. 2013, 25, 1296.

[84] Y. Yang, M. C. Gupta, K. L. Dudley, R. W. Lawrence, Nano Lett. 2005, 5, 2131.

[85] H.-B. Zhang, Q. Yan, W.-G. Zheng, Z. He, Z.-Z. Yu, ACS Appl. Mater. Interfaces 2011, 3, 918.

[86] J. H. Johnston, J. Moraes, T. Borrmann, Synth. Metals 2005, 153,65 .

[87] L. Mattoso, E. Medeiros, D. Baker, J. Avloni, D. Wood, W. Orts, J. Nanosci. Nanotechnol. 2009, 9, 2917.

[88] I. Bayer, V. Caramia, A. Biswas, R. Cingolani, A. Athanassiou, Appl. Phys. Lett. 2012, 100, 201604.
www.MaterialsViews.com

[89] R. Wang, J. Sun, L. Gao, C. Xu, J. Zhang, Chem. Commun. 2011, $47,8650$.

[90] J. E. Mates, I. S. Bayer, M. Salerno, P. J. Carroll, Z. Jiang, L. Liu, C. M. Megaridis, Carbon 2015, 87, 163.

[91] U. J. Lee, S.-H. Lee, J. J. Yoon, S. J. Oh, S. H. Lee, J. K. Lee, Sol. Energy Mater. Sol. Cells 2013, 108, 50.

[92] F. Ayadi, I. S. Bayer, D. Fragouli, I. Liakos, R. Cingolani, A. Athanassiou, Cellulose 2013, 20, 1501.

[93] A. Saeed, H. Zuhailawati, A. Ismail, Z. Samad, T. Ariga, Int. J. Adv. Manuf. Technol. 2014, 73, 591.

[94] D. Chung, Carbon 2001, 39, 279.

[95] N. Li, Y. Huang, F. Du, X. He, X. Lin, H. Gao, Y. Ma, F. Li, Y. Chen, P. C. Eklund, Nano Lett. 2006, 6, 1141.

[96] J. Lloyd-Hughes, T.-I. Jeon, J. Infrared Millimeter, Terahertz Waves 2012, 33, 871 .

[97] A. Das, T. M. Schutzius, C. M. Megaridis, S. Subhechha, T. Wang L. Liu, Appl. Phys. Lett. 2012, 101, 243108.

[98] D.-X. Yan, P.-G. Ren, H. Pang, Q. Fu, M.-B. Yang, Z.-M. Li, J. Mater. Chem. 2012, 22, 18772.

[99] J. Liang, Y. Wang, Y. Huang, Y. Ma, Z. Liu, J. Cai, C. Zhang, H. Gao, Y. Chen, Carbon 2009, 47, 922.

[100] H. Kim, K. Kim, C. Lee, J. Joo, S. Cho, H. Yoon, D. Pejakovic, J.-W. Yoo, A. Epstein, Appl. Phys. Lett. 2004, 84, 589. 